\title{
Author Spotlight: Sun Jung Oh
}

\section{Sun Jung $\mathrm{Oh}^{1}$}

Accepted: 18 February 2021 / Published online: 25 March 2021

(c) The Author(s), under exclusive licence to Springer Science+Business Media, LLC, part of Springer Nature 2021

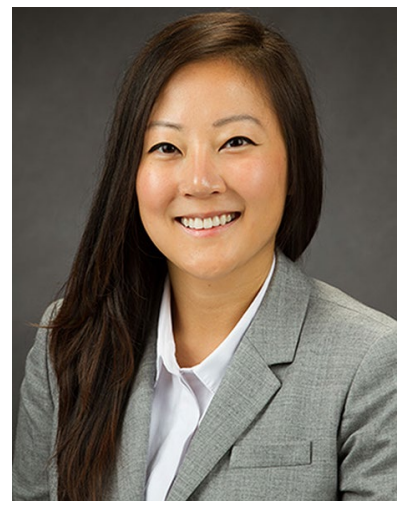

Sun Jung (Sunny) Oh is currently a second-year fellow at Johns Hopkins University Division of Gastroenterology and
Hepatology. Following her degree of a B.S. in psychology as an undergraduate at Carnegie Mellon University, she worked at a bioengineering lab in University of Pittsburgh for 3 years where she developed her interest in medicine and research. She received her medical degree at Medical College of Georgia and completed her internal medicine residency at Cedars-Sinai Medical Center in Los Angeles, CA. She has an interest in GI motility disorders and gut microbiome, as well as health outcomes research and medical education. She hopes to continue her career in academic gastroenterology after graduating from fellowship.

Publisher's Note Springer Nature remains neutral with regard to jurisdictional claims in published maps and institutional affiliations.

Sun Jung Oh

oh.sunjung@gmail.com

1 Johns Hopkins Hospital, Baltimore, MD, USA 